\title{
Crise-regeneração paradigmática da Sociologia e sistema econômico
}

\section{RENATO P. SAUL}

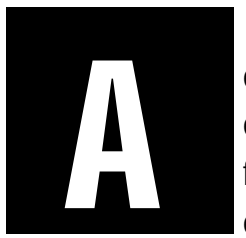

análise do atual estado das Ciências Sociais é uma tarefa de difícil realização em virtude não apenas da amplitude das mutações em curso como também em razão da profundidade em que se processam e das conseqüências que deixam antever. Concorre de modo fundamental para as dificuldades de análise o fato de que tais amplitude, profundidade e antevisões otimistas e pessimistas têm origem na constatação de que as mudanças derivam de uma convergência de circunstâncias e de tendências cujo núcleo é uma sucessão de questões paradoxais.

Assim, por exemplo, nesse movimento se desenha um largo espectro de possibilidades de avanços nas Ciências Sociais, através de inúmeras direções alternativas e contraditórias. Registram-se também versões do processo em andamento, que sustentam a ocorrência de uma inevitável unificação, não apenas das Ciências Sociais, mas das ciências como um todo.

Nosso propósito aqui é arriscar, embora timidamente, uma aproximação a esse conjunto de situações novas, buscando identificar alguns elementos considerados significativos.

Para desenvolver nossa análise a respeito do movimento em curso, duas questões preliminares se impõem. A primeira diz respeito à concepção de crise que utilizamos aqui. Ela é aplicada a duas situações: ao panorama econômico internacional e às transformações que se operam no pla-

\footnotetext{
* Professor titular aposentado do Instituto de Filosofia e Ciências Humanas da UFRGS. Integrante do núcleo de estudos Violência e cidadania da UFRGS. Professor do Curso de pós-graduação em Ciências Sociais Aplicadas da Unisinos.
} 
no paradigmático da Sociologia. A noção de crise indica o momento agudo de um processo, que ocorre como resultante da atuação simultânea de forças sociais concretas e antagônicas, atuando como energias degenerativas e regenerativas, ao mesmo tempo. N esse caso, as crises se verificam como produtos de tensões cujo campo de realização envolve o plano material e o plano intelectual e, no seu interior, estão contidas múltiplas possibilidades de resolução ou de acomodamento das situações agudas. Isso implica dizer que, no próprio momento da crise, seus componentes sociais ativos, internos e externos, na medida em que negam determinadas condições, apontam para outras e comportam elementos de sua justificação e sustentação. Em segundo lugar, a ênfase do texto no desenvolvimento da ciência sociológica não tem a pretensão de realizar uma redução das Ciências Sociais a um campo disciplinar particular. Essa ênfase se verifica por entendermos que a Sociologia representa o pivô de uma profunda transformação em curso desde cerca de quarenta anos, afetando to do o circuito do pensamento social.

Posto isso, pensamos que uma perspectiva do estado das Ciências Sociais hoje em dia pode ser examinada utilizando-se como foco de aproximação duas afirmativas de autores bem diferentes. A primeira observação é de Antonio Gramsci, formulada em um dos fragmentos constantes de seus escritos do cárcere e publicados postumamente. Diz Gramsci:

O êxito da sociologia está em relação com a decadência do conceito de ciência política e de arte política que tem lugar no século XIX (com mais exatidão na segunda metade, com o êxito das doutrinas evolucionistas e positivistas). Aquilo que é realmente importante na sociologia é a ciência e a arte políticas (Gramsci, 1975, p. 1765).

A outra afirmativa pertence ao cientista social alemão Claus Offe, divulgada em diferentes publicações que circularam no Brasil em fins dos anos oitenta, e datada do início dessa década. A observação de O ffe diz: 
As tradições clássicas da sociologia burguesa assim como da marxista compartilham do ponto de vista de que o trabalho é o fato social principal. Eles concebem a sociedade moderna e sua dinâmica central como uma "sociedade do trabalho" (Offe, 1989 a, 167; b, 13; c, 5).

Essas duas afirmativas, separadas não apenas no tempo - mais de cinqüenta anos - mas também pelos vieses epistemológicos e pelas circunstâncias políticas que as orientam, sinalizam aspectos cruciais da evolução das Ciências Sociais a partir do século dezenove: a divisão do trabalho, com a economia e uma extraordinária sensibilidade para as transformações do sistema econômico derivada da sua intimidade com os problemas atinentes às relações de poder que vêm embutidas naquelas transformações.

Em primeiro lugar, considerando-se o desenvolvimento das Ciências Sociais a partir do momento em que elas começam a adquirir foros de disciplinas acadêmicas, observa-se uma estreita parceria entre elase a Economia. Isso é mais evidente quando se examina o desenvolvimento da Sociologia. U ma das questões mais notáveis, nesse sentido, é o fato de se perceber a existência de uma divisão de tarefas entre, por exemplo, a Sociologia e a Economia na segunda metade do século passado, especialmente no que se refere ao tratamento da questão da propriedade. De certo modo, a história da propriedade deixa de ser ser objeto da Economia e passa a ser uma das preocupações da Sociologia. M ais interessante ainda é o fato de que por trás dessa divisão de tarefas está um elemento decisivo do desenvolvimento da Sociologia como disciplina acadêmica, que é o esforço de retirar de seus ombros a tese do socialismo científico, com 0 qual ela aparecera confundida. As marcas registradas dessa condição parecem ser as antinomias que caracterizaram a evolução da Sociologia ao longo do tempo e que hoje tendem a perder expressão, muito embora nas cinzas deste passado ainda brilhem brasas vivas: as antinomias presentepassado, idiográfica-nomotética e mundo civilizado-mundo bárbaro. Este foi o curso de sua atuação na busca de formas alternativas de poder, consentâneas com a sociedade industrial emergente. 
As duas afirmativas apontadas realçam que o leitmotiv que orienta a tendência histórica do desenvolvimento da Sociologia se conforma na polarização entre economia e política, as outras áreas aparecendo, de início, como pontos cuja relevância se alterna, girando em torno da polarização, segundo conveniências ou interesses do momento.

Buscando esquematizar esse movimento, poderíamos imaginar o espaço de abrangência da Sociologia envolvendo vários campos de atuação com seu eixo principal definido pelos campos da Economia e da Política:

Indivíduo/sociedade

(Persona)

Economia

História Política

Cultura

Apósa 2a Guerra M undial, fatos de transcendental importância se verificaram no plano mundial, resultando em mudanças substantivas no plano das relações econômicas e políticas, nacionais e internacionais. Esses fatos são a crise do Estado do Bem-Estar e o processo de globalização econômica.

A crise do Estado do Bem-Estar, também denominada como crise do consenso keynesiano de política econômica, anunciou o fim dos "anos gloriosos" da economia mundial, isto é, os trinta anos que se seguem à Segunda Guerra Mundial, e implicou, em termos econômicos, o questionamento do sistema de intervenção estatal na organização das economias nacionais, nos planos macro e micro, através da planificação global ou setorial e pela sua atuação direta ou indireta na condução de atividades e empresas atuantes na infra-estrutura de comunicações e transportes ou no setor financeiro.

Do ponto de vista político, essa crise marca a ruptura do pacto político que havia fundado a prática de concessão de serviços de previdência e seguridade social, de garantias de emprego e de condições de sobrevivência em situações de desemprego, de aposentadoria e velhice. 
A crise do consenso keynesiano ocorre dentro de um movimento regenerativo da economia e da política mundiais, no qual a mediação estatal se realiza por uma dinâmica social inversa à anterior. 0 s instrumentos operativos principais são três estratégias integradas - a privatização dos setores públicos, a desregulamentação das relações econômicas e sociaise a integração dos mercados nacionais. Sob as engrenagens dessa operação, foi triturado o pacto social-democrata que suportou o Estado do BemEstar. Esta pode ser considerada, do ponto de vista social e sociológico, a dinâmica central do que se intitulou processo de globalização econômica.

Paralelamente à ocorrência desses fatos, um conjunto de modificações se verifica no plano das Ciências Sociais, implicando um movimento de reorientação do campo científico tanto no plano dos desenvolvimentos teóricos quanto no plano das metodologias de pesquisa e suas aplicações práticas. Essa reorientação tomou corpo no que foi caracterizado posteriormente como crise dos paradigmas (lanni, 1990). Processo de longo curso cujo efeito foi, na realidade, uma espécie de "explosão paradigmática", tendo em vista que ela comportou, nos seus efeitos, a emergência de um sem número de vertentes novas, configurando propostas de sendas alternativas para o encaminhamento da ciência dentro do que se descortinava como outra configuração do mundo.

É difícil, praticamente impossível, elencar as tendências resultantes, tal a quantidade de direções propostas. Arriscando cometer algumas impropriedades nesta incursão classificatória, podemos identificar algumas das grandes linhas desse movimento. Linhas essas que não representam posições mutuamente excludentes.

Em primeiro lugar, registra-se uma tendência no sentido da negação das teorias sociais. Essa tendência faz parte da chamada crítica pós-moderna à teoria social. De acordo com um dos seus pensadores mais representativos, Jean-François Lyotard, o pensamento pós-moderno corresponderia a uma desconfiança com relação às metanarrativas (1984). 0 seu ponto principal, no contexto do pensamento sociológico, parece ser o de buscar 
uma integração multidisciplinar das narrativas. Assim, considerando que o "social" se apresenta de modo extremamente problemático, a proposta ganha consistência afirmando a necessidade da sua substituição por uma diversidade de teorias sociais, único modo de dar conta dos aspectos multidimensionais da vida social.

Em segundo lugar, pode-se considerar a tendência no sentido de buscar-se a construção de uma síntese das propostas teóricas divergentes. Vários autores e direções podem ser identificadas nessa linha. Um dos sociólogos mais proeminentes nesse aspecto é Jeffrey Alexander. Fazendo equivaler teoria e pressupostos gerais sobre a ação humana e a ordem social, este autor argumenta com a convergência existente nesse plano entre grande parte das teorias clássicas e contemporâneas. 0 novo movimento tem como conteúdo uma síntese multidimensional tanto normativa como instrumental da ação e da ordem. Anthony Giddens pode ser um outro exemplo de proposta no sentido de realização de uma síntese que supere a competição entre as teorias no passado. Sua teoria da estruturação pretende ir muito além de uma teoria social, quer ser uma ontologia social (Giddens, 1989). Num sentido integrador pode também ser pensado o projeto Open the Social Sciences, da Comissão Gulbenkian de Reestruturação das Ciências Sociais, cujos objetivos transcendem um mero rearranjo disciplinar envolvendo a perspectiva de um largo esforço organizacional e interdisciplinar, articulado através da conjugação de iniciativas de instituições voltadas para o ensino e a pesquisa nas Ciências Sociais (Calouste Gulbenkian Commission, 1996).

U ma outra direção se verifica no sentido da rejeição das incursões no plano epistemológico e ontológico, tal como a discussão macro-micro, agência-estrutura, etc. Esta proposta tem como principal tarefa teórica da Sociologia a construção de instrumentos analíticos, conceitos instrumentais, diretrizes interp retativas voltadas para problemas empíricos. U m exemplo dessa posição é Pierre Bourdieu e sua preocupação com um conjunto de conceitos centrais, como habitus (como conjunto de disposições para a 
ação e percepção que opera a partir dos agentes sociais) e campo (a configuração de relações entre posições sociais, ou espaço estruturado onde se desenrolam os conflitos). O utra linha que se poderia enquadrar dentro dessa tendência são os programas de investigação orientados dentro do individualismo metodológico. Compreendendo diferentes posições, essa tendência concentra-se na construção de modelos formais dos processos, através do quais diferentes atores sociais, buscando a maximização da utilidade (ou dos seus interesses), interagem de forma a alcançarem resultados sociais. Assim procedendo, tais teorizações buscam integrar a estrutura social em modelos de ação individual, ou em outros termos, no sentido de buscar os microfundamentos das estruturas sociais.

Por último, podem-se mencionar duas direções no que respeita à consideração dos clássicos. São direções contraditórias: uma se apresenta afirmando a necessidade da sua superação (Giddens, Touraine, Alexander); outra afirma necessidade inversa, da valorização dos clássicos através do desenvolvimento de novas esquemas interpretativos. Assim, por exemplo, nota-se um esforço bastante importante no sentido da recuperação da contribuição de autores como George H. M ead, Georg Simmel, Georges Gurvitch, entre muitos outros.

A verificação da ocorrência dessa "explosão paradigmática" paralelamente com a crise do consenso keynesiano parece não ser produto de mera coincidência, mas sim o desenvolvimento de uma conjugação de questões que, ora derivam das transformações, ora fornecem subsídios teórico-metodológicos para sua implementação. Alguns acontecimentos podem ser lembrados no sentido de indicar essa articulação.

U $m$ deles é a constatação de uma crise de cientificidade que envolveu a Sociologia na passagem dos anos setenta-oitenta. Existem várias hipóteses que se podem levantar na busca das causas para este fato. A mais importante delas aparece relacionada com o processo de vulgarização experimentado pelas pesquisas científicas na área, dentro do movimento que Salvador Giner caracterizou como êxito mundano da sociologia $(1994,166)$. 
A crise também pode ser vista pela perspectiva da capacidade preditiva da ciência. Se imaginarmos o processo de predição científica regido por dois princípios, um que afirma ser a lógica da predição idêntica à da explicação e outro afirmando ser a predição um juízo do presente, podemos ter uma idéia da amplitude dos tensionamentos em processo. No que respeita ao primeiro princípio, as Ciências Sociais sempre enfrentaram grandes dificuldades no seu desenvolvimento. Das importações metodológicas do campo econômico, temos dois exemplos importantes: a lei de tendência e a cláusula ceteris paribus. A vulgarização da pesquisa científica nesta área contribuiu decisivamente para o aumento do grau de frustração diante da constatação do fracasso das expectativas quanto à capacidade de antevisão dos desdobramentos das crises sociais e políticas que emergiam. 0 outro princípio da predição diz respeito ao fato de que ela implica um juízo do presente, isto é, é expressão abstrata de um esforço para criar uma vontade política. De novo, aqui, as Ciências Sociais conviveriam com a frustração de um amplo leque de expectativas criadas, especialmente em torno das direções que o sistema econômico mundial poderia tomar e das transformações políticas subseqüentes. 0 ano de 1968 surge como marco de uma transformação decisiva neste sentido. Parece ser uma consequência exemplar desse fato a crítica e a crise do marxismo, em meados dos anos setenta tanto no plano teórico quanto no plano político.

O utro acontecimento a ser lembrado é a crítica desenvolvida em torno da noção de trabalho como núcleo articulador da Sociologia. Esta tendência se difunde no meio especializado brasileiro, através da obra de Claus 0 ffe citada no início deste texto, partindo de estudos realizados na Alemanha, tendo como núcleo a idéia de desaparecimento da sociedade do trabalho (expressão criada por Ralf $D$ aherendorf) e fundamentada filosoficamente nos trabalhos de Jurgen $\mathrm{H}$ abermas, datados dos anos sessenta, onde este autor desenvolve a crítica de uma ontologia fundada no trabalho. Habermas também usa como elemento de construção de seu ponto de vista a crise de legitimidade que se verificaria no capitalismo tardio 
onde posteriormente se definiria o processo de emergência de um novo paradigma - o paradigma da comunicação - em substituição ao paradigma do trabalho. Na raiz, a teoria de O ffe representava uma estratégia de refundação das Ciências Sociais, processando o deslocamento da presumida matriz das relações de trabalho para o universo do mercado, transformando o capítulo do trabalho na Sociologia num exercício de Economia Política.

U ma tal contribuição no terreno da teoria social assentou perfeitamente no universo econômico da globalização onde as condições de realização do trabalho estariam experimentando radical transformação em obediência a circunstâncias novas que se verificavam no terreno da produção, derivadas estas últimas de uma nova configuração do mercado mundial.

U ma terceira ocorrência a ser considerada e que aponta de forma inequívoca para a articulação com os acontecimentos envolvendo a ruptura da política econômica de estilo keynesiano é a crise que cerca a noção de desenvolvimento e a discussão em torno da sua aplicabilidade ao contexto da periferia do sistema capitalista, representando o prenúncio de novas formulações teórico-práticas do desenvolvimento da economia mundial. Trata-se do novo contexto de articulação-subordinação das diferentes regiões do globo sob o império do processo de globalização.

É preciso lembrar aqui uma circunstância muito especial que envolve o desenvolvimento das Ciências Sociais na América Latina. 0 período que se segue à Segunda Guerra marca um momento bastante especial na atuação dos cientistas sociais latino-americanos. A análise do sistema capitalista internacional e as conseqüências das transformações operadas na divisão internacional do trabalho parecem ser uma fonte extremamente rica para o exercício da intelectualidade latino-americana. A difusão do modelo keynesiano de política econômica realizou-se apoiado por uma teorização sobre a periferia do sistema, os países "atrasados" do sistema capitalista. A teoria da modernização juntamente com a teoria do dualismo estrutural tiveram, neste aspecto, papéis complementares. A teoria da modernização 
procurou estabelecer, além de uma explicação para o fenômeno, os fundamentos de uma evolução dos países atrasados por um processo de superação de etapas, cujos extremos eram localizados entre o tradicional e o moderno. A teoria do dualismo estrutural procurou realçar os contrastes existentes nos países atrasados, marcados pela contradição tanto econômica quanto política e social produzida em razão da coexistência de setores modernose arcaicos. As teorizações nesse plano caracterizaram-se nitidamente por terem como elemento central uma estratégia de regionalização do desenvolvimento internacional orientado pelas nações avançadas.

É a partir de uma visão crítica dessa teorização que se desenha a busca da intelectualidade latino-americana em direção de alternativas científicas para explicação das manifestações contraditórias do capitalismo periférico.

A teoria do desenvolvimento produzida pela Comissão Econômica para a América Latina (CEPAL), de 1949, representou um esforço inédito de sistematização do pensamento latino-americano sobre a questão do desenvolvimento, colocando o problema do desenvolvimento regional numa perspectiva estratégica, orientada a partir da América Latina, afirmando o desenvolvimento autônomo. Com isso, inverteu a perspectiva política que estava contida naquelas teorizações.

$\mathrm{Na}$ primeira metade dos anos sessenta, tem lugar a emergência de um novo enfoque sobre as condições de realização do capitalismo na América Latina e se estabelecem os confrontos com as teorias do desenvolvimento e da modernização e também com a teoria cepalina do desenvolvimento autônomo. A teoria da dependência e a teoria do subdesenvolvimento em torno da qual marcaram presença Ruy Mauro Marini, Florestan Fernandes, Agustin Cueva, Vania Bambirra, Teotonio dos Santos, O ctavio Ianni, D arcy Ribeiro, Fernando Henrique Cardoso, Enzo Faletto, M arcos Kaplan e tantos outros, caracterizou-se, dentro de seus vários matizes, por ser uma reflexão que pretendeu e demonstrou que a experiência latino-americana compreendia um modo especial de realização do capita- 
lismo, no qual se processava uma articulação entre setores sociais internos e internacionais e as condições de realização do desenvolvimento econômico se caracterizavam pela reprodução da surbordinação, aprofundando a dependência externa. Este empreendimento teórico comportou vários matizes na avaliação do quadro existente na economia latino-americana, indo da crítica às políticas monitoradas desde o exterior nos rumos da economia nacional a proposições de ruptura violenta com o esquema de dominação vigente.

Nos anos setenta, especialmente após o golpe de Pinochet no Chile e a derrota da Unidade Popular chilena, as propostas e o sentido teórico e programático contidos naquela discussão começaram a perder fôlego, especialmente em sua dimensão política. Nos anos 80 , seu conteúdo econômico e político sofreu um processo de reciclagem, sendo incorporado à dinâmica de uma nova etapa da divisão internacional do trabalho. A perspectiva do processo de globalização econômica foi concomitante com uma mudança decisiva no contexto dos modelos de análise sociológica da realidade latino-americana.

O s três acontecimentos referidos não são apenas os elos de articulação das Ciências Sociais e da Sociologia com as transformações que se verificaram no contexto da economia mundial entre os anos sessenta e oitenta, como constituem o leito por onde fluem as novas direções paradigmáticas assinaladas. Algumas delas servem de suporte teórico e justificativa para as tranfformações em curso.

Evidência desse processo é a atuação do Conselho Latino-Americano de Ciências Sociais (CLACSO ). Funcionando como uma espécie de apareIho sensor das transformações que iam em curso, o CLACSO, na segunda metade da década de oitenta, passou a considerar a necessidade de reformular o paradigma de explicação da estrutura social, de modo a adequá-lo às condições emergentes na realidade mundial e regional. $\mathrm{Na}$ perspectiva do CLACSO , os modelos de análise da realidade utilizados nas Ciências Sociais e na Sociologia em particular estavam envelhecidos e se 
apresentavam insuficientes face à "desarticulação" e à "desagregação" da sociedade regional. Do ponto de vista estatal, a questão tornava-se imperiosa face à necessidade de considerar os problemas emergentes numa perspectiva realista e, desde o ponto de vista da economia, apresentava-se de forma crucial o problema da "ingovernabilidade" engendrada pelasnovas situações. Na mesma medida em que os "movimentos sociais totalizantes" (classes sociais) perdiam substância, a perspectiva dos "novos" movimentos sociais, neste caso, embora ensejassem "novas visibilidades", não apresentava resultados satisfatórios. Tornava-se necessário atualizar e consolidar instrumentos diferentes para dar conta dos novos atores sociais, cujas demandas, de forte carga simbólica, punham em risco as relações de poder existentes (CLACSO, 1987a e 1987b). Realismo político e ingovernabilidade são os pontos de sustentação do modelo que irá substituir os instrumentos de análise até então utilizados. Ficava evidente nas suas manifestações que as Ciências Sociais enfrentavam a necessidade de buscar outras formas de representação política da sociedade e do social e que os problemas de representação estavam relacionados às possibilidades de realização da democracia e do desenvolvimento econômico na região (CLACSO, 1987a). Nessa época e com esse intuito, o CLACSO patrocinou um grande número de estudos nos quais a questão condutora era a busca e a identificação de atores sociais e culturais, com vistas a estabelecer a renovação das bases da ordem estatal na região e da sua harmonia com o resto do mundo.

Nos anos noventa, descortinou-se para as Ciências Sociais uma outra perspectiva. $\mathrm{N}$ a verdade, essa perspectiva não era realmente uma novidade, tratava-se de um movimento que então passava a adquirir uma visibilidade que não possuía. Suas origens estão vinculadas à terceira revolução tecnológica, a revolução cibernética, e à emergência das chamadas Ciências da Cognição, entre 1940 e 50. Referimo-nos aos estudos da complexidade ou ciências da complexidade. Compreendendo uma ruptura com concepções dominantes de ciência, os estudos da complexidade estariam 
patrocinando um processo de reconceituação da ciência a partir de uma aproximação das demais ciências às ciências sociais. Esse processo representaria uma inversão de direção na aproximação entre os campos científicos. A ênfase na contingência, na dependência contextual múltipla, ultrapassando estruturas espaço-temporais, moveria as ciências naturais em direção às Ciências Sociais e históricas e suas concepções, no que respeita a totalidades espaço-temporais compreendidas em estruturas relacionais de interação humana e o tempo fenomenológico de desenvolvimento, das quais estas últimas são inseparáveis. Assim, a nova concepção de ciência envolveria a rejeição da possibilidade da predição, a percepção da normalidade dos sistemas que se movem fora de equilíbrio com suas inevitáveis bifurcações, estruturas dissipativas e a centralidade da "flecha do tempo". O que parece ser mais relevante na discussão em processo atualmente é a ênfase na criatividade autoconstitutiva do processo natural e da não-distinção entre homem e natureza, com a conseqüente assunção de que a ciência é uma parte integral da cultura.

Um dos maiores sociólogos americanos da atualidade, Imannuel W allerstein, juntamente com outros colegas atuantes no Fernand Braudel Center, da Binghamton University, de New York, sustentam uma visão otimista desses estudos na resolução de problemas que envolvem as Ciências Sociais desde as suas origens. É um otimismo cauteloso, pois define-se em termos de um futuro distante. W allerstein vaticina que, num período localizado daqui a vinte e cinco ou cinqüenta anos, as novas direções científicas em processo, atuando no sentido da unificação das ciências, produzirão a superação da divisão do conhecimento em duas culturas, engendrada em meados do século dezoito como resultante da separação entre ciência e filosofia. A partir desse momento, no terreno das Ciências Sociais, não haveria mais lugar para as antinomias entre local e global, macro e micro e entre agência e estrutura. Assim, não haveria mais espaço para a divisão entre os campos político, econômico e sociocultural do conhecimento e para a vigência ou aceitação da cláusula ceteris paribus, que mar- 
cou de forma decisiva a trajetória do desenvolvimento das Ciências Sociais até aqui. 0 corre, entretanto, que no período que medeia entre esse lapso de vinte e cinco-cinqüenta anos, as dificuldades a vencer serão enormes, tendo em vista que as Ciências Sociais, não obstante caminhem em direção à unificação, elas o fazem em enorme confusão e um infindável número de variações. Isso ocorreria em virtude de que, dos três grandes fatores que estariam atuando decisivamente no terreno do conhecimento globalização, ciências da complexidade e difusão dos estudos culturais -, os dois últimos não afetaram decisivamente as Ciências Sociais. De modo significativo, Wallerstein aponta como raiz do problema o sistema capitalista, que utiliza uma versão determinística de ciência como um véu cultural para investir na tecnolocia e na ciência, para "conquistar" a natureza em nome de um inevitável e inquestionável progresso científico. A condição fundamental para uma transformação no mundo do conhecimento estaria intrinsecamente vinculada a uma transformação do sistema mundial (W allerstein, 1997 e 2000).

D evemos, neste ponto, voltar a considerar as duas frases, de Gramsci e $\mathrm{O} f f e, c o m$ as quais abrimos estas considerações e que procuravam encaminhar nosso argumento de que a Sociologia foi marcada por um indisfarçável compromisso com o campo político e econômico.

A perspectiva desenhada para o futuro do conhecimento científico de um modo geral e das Ciências Sociais em particular, a partir da década de noventa, apontada para uma virtual unificação das ciências, apresenta uma dimensão que já se manifestava de modo flagrante nas soluções paradigmáticas buscadas nos anos setenta e oitenta. Essa dimensão é a definida pelo vetor mercado como centro dinâmico da construção do conhecimento.

A expressão mais saliente dessa tendência era a perspectiva de uma ciência social de tipo normativo na qual a questão da previsão se realizava pela construção de modelos de ação racional baseados na composição de grupos de interesses organizados, reconhecidos e legitimados socialmente. 
Com ela contracenava a busca de novos atores sociais, esforço típico dos estudos levados a efeito sob patrocínio do CLACSO, nos anos oitenta e inícios dos anos noventa.

Não é casual perceber-se, por trás dessas percepções, a idéia dos processos sem sujeito, típicas da visão liberal que vem de Adam Smith ("mão invisível"), passa por Friederich von Hayek e pelo estruturalismo de Louis Althusser e culmina nas teorias da autopoiésis ou da auto-organização, que surgem no horizonte intelectual como uma das direções decisivas dos estudos da complexidade. Exemplar a esse respeito é a forma como a "flecha do tempo" incorpora-se na teoria organizacional, de modo a indicar uma permanente convergência do movimento em direção à maior ordem e complexidade, de comportamentos não-ótimos em direção a comportamentos ótimos, alcançando o ótimo através da variação extrema dos prévios comportamentos sub-ótimos.

Aqui nos encontramos com uma questão que, do nosso ponto de vista, é decisiva no desenvolvimento atual e futuro das Ciências Sociais.

Algumas características no tratamento da questão do conhecimento parecem definir uma outra dimensão do futuro pouco visível das Ciências Sociais hoje em dia. Juntamente com as decantadas novas virtudes do conhecimento unificado, encontramo-nos com horizontes bastante comprometidos com uma perspectiva preocupante. A gama de características de uma ciência unificada, tais como a impossibilidade intrínseca da previsão, a centralidade da "flecha do tempo", os sistemas fora de equilíbrio e as suas estruturas dissipativas, a autocriatividade organizativa, etc., leva alguns autores a sugerirem perspectivas de superação de alguns problemas importantes que dividem os campos do conhecimento nas Ciências Sociais. Este processo representaria a supressão do dilema voluntarismo-determinismo que está subjacente ao debate macro-micro, agência-estrutura, global-local.

É preciso considerar, nesse quadro, alguns pontos importantes. Em primeiro lugar, os debates em torno de questões envolvendo os campos de atuação das Ciências Sociais possuem uma dimensão muito mais ampla 
que a discussão em torno de linhas demarcatórias de proposições epistemológicas e de seus encaminhamentos teórico-metodológicos. Se o dilema ou antinomia voluntarismo-determinismo é dado como subjacente a tais debates é porque neles está embutida a questão ético-política fundadora do pensamento científico nas Ciências Sociais. Condição que se pretende estar fora da esfera de abrangência das outras ciências (não-sociais), como se elas tivessem permanecido ao longo de sua evolução intocadas pelos variações e instabilidades da vida econômica e política. Todo o debate e toda a nebulosa que envolve as transformações pelas quais passam as Ciências Sociais hoje em dia têm por centro essa questão. 0 dilema voluntarismo-determinismo é, em nosso ponto de vista, parte da dinâmica organizatória do processo científico na Sociologia e, portanto, insuperável, independentemente de prazos longos ou curtos. A nós parece que qualquer perspectiva de superação desse conflito original e definitivo é cair no determinismo puro e simples dos processos sem sujeito.

De outra parte, deve-se considerar que há uma notável coincidência entre a difusão das teorias do caos e da complexidade e os desequilíbrios que a economia mundial vem apresentando desde os anos oitenta. Haverá alguma articulação histórica entre o fato de a economia atual (orientada pela princípio da mass customization) não corresponder a uma concepção de economia fundada no equilíbrio (típica da fase de mass production)? Vários livros nas áreas de economia e organização, divulgados recentemente, apontam no sentido afirmativo (ver por exemplo: Parker, 1994; Davis \& M eyer, 1999; O rmerod, 1999). Pode-se considerar também um outro aspecto importante envolvido na questão, que é o seguinte: em que medida aquilo que se apresenta hoje como último grito do avanço das ciências não é nada mais do que a reiteração de velhas fórmulas derivadas do pensamento econômico nas quais a interação livre dos sujeitos indeterminados cumpre o circuito equilíbrio-desequilíbrio-equilíbrio sob a regência de uma supra-racionalidade sistêmica? 
Diante das perspectivas que se desenham no horizonte sociológico da atualidade é preciso recordar um outro fato que marca a trajetória do desenvolvimento das Ciências Sociais. A convivência com a instabilidade e o desequilíbrio foi uma constante ao longo de sua trajetória em diferentes áreas de atuação. Como observou José Nun:

as leis de causalidade que às vezes invocamos tendem a ser meramente estatísticas, nossas explanações sobre 0 passado ou sobre o presente são muito parciais para serem estendidas no tempo como previsões do que irá ocorrer, e o nosso objeto de estudo é altamente heterogêneo e instável. Entretanto, se não podemos fazer previsões, podemos formular conjeturas plausíveis (N un, 2000, p.6).

No que respeita às tendências em vista, é importante reter o que diz José N un, no início da reflexão reproduzida acima: há muito pouco que se possa dizer de verdadeiro a respeito do futuro das Ciências Sociais. A menos que se pretenda sustentar a imperecibilidade do presente, acrescentamosnós.

\section{Referências bibliográficas:}

CALO USTE GU LBEN KIAN COM M ISSIO N. O pen the Social Sciences. Lisboa: Fundação Calouste Gulbenkian, 1996.

CLACSO (Consejo Latinoamericano de Ciencias Sociales). Concertación políticosocial y democratización. Buenos Aires: CLACSO, 1987a.

CLACSO (Consejo Latinoamericano de Ciencias Sociales). Seminário: Transformaciones de la estrutura social latinoamericana. Relatório. Secretaria Ejecutiva del CLACSO, Buenos Aires: 1987b (mimeo.).

DAVIS, S. \& MEYER, C. Blur: A velocidade da mudança na economia integrada. Rio de Janeiro: Campus, 1999. 
GIDDENS, Anthony. A constituição da sociedade. São Paulo: Martins Fontes, 1989. GINER, Salvador. La inteligencia sociológica, una victoria incierta. Sociológica, ano 9, n 24, (enero-abril 1994) p. 163-181.

GRAMSCI, Antonio. Q uaderni del carcere. edizione critica dell'istituto Gramsci a cura Valentino Gerratana. Torino: Einaudi Editore, 1975.

IAN NI, O ctavio. A crise de paradigmas da Sociologia. Revista Brasileira de Ciências Sociais, numero 3 ano 5 (junho 1990), p. 90-100.

LYOTARD, Jean-François. A condição pós-moderna. Lisboa: Gradiva, 1989.

NUN, Jose. The end of work and the "marginal mass" thesis. Latin American Perspectives. Vol 27 n.1 (january 2000), p: 6-32.

OFFE, Claus (a). Capitalismo desorganizado. São Paulo: Brasiliense, 1989.

(b). Trabalho e sociedade. Problemas estruturais e perspectivas para 0 futuro da sociedade do trabalho (Volume 1: A crise). Rio de Janeiro: Tempo Brasileiro, 1989.

(c). Trabalho: categoria chave da Sociologia. Revista Brasileira de Ciências Sociais. N 10, vol 4 (junho de 1989), p.5-20.

ORMEROD, P.. Butterfly economics: a new general theory of social and economic behavior. N.York: Coronet Books, 1999.

PARKER, D . \& STACEY, R.. Chaos, management and economics: the implications of non-linear thinking. London: Institute of Economic Affairs; Pantheon Books, 1994.

W ALLERSTEIN, Immanuel. Social Science and the quest for a just society. American Journal of Sociology, vol 102 n. 5, march/1997, p. 1241-57.

. From sociology to historical Social Science: prospects and obstacles. The British Journal of Sociology, vol 51, n. 1 (January/march 2000), p. 25-35. 


\section{Resumo}

Trata o presente texto de análise de aspectos do estado atual de desenvolvimento da Sociologia, utilizando como ponto de partida a polarização de suas preocupações, definidas entre o campo da economia e da política. Busca, neste sentido, estabelecer a conexão histórica entre as transformações paradigmáticas experimentadas pela Sociologia nos últimos quarenta anos, a crise da política econômica keynesiana, juntamente com seus desdobramentos na esfera das relações políticas, e o processo de globalização. Ensaia também uma análise das perspectivas que se apresentam à disciplina em face do conjunto de situações novas que se delineiam no horizonte da evolução do processo de conhecimento, especialmente a partir da difusão das teorias que sustentam a unificação dos campos científicos.

Palavras-chave: Sociologia, mudanças paradigmáticas, teoria social, pensamento social. 